07.2

\title{
Аномалии частотной отсечки полупроводниковых диодов на сверхвысоких частотах
}

\author{
(C) Г. Абдурахманов ${ }^{1,2}$, А. Есбергенова ${ }^{1,2}$, C. Рейимбаева ${ }^{1}$ \\ ${ }^{1}$ Национальный университет Узбекистана, Ташкент, Узбекистан \\ ${ }^{2}$ Научно-технический центр АО „Узбекэнерго“, Ташкент, Узбекистан \\ E-mail: gulmirzo@mail.ru
}

Поступило в Редакцию 13 июля 2020г.

В окончательной редакции 15 сентября 2020 г.

Принято к публикации 15 сентября 2020г.

\begin{abstract}
Представлены результаты экспериментального исследования частотной зависимости детектированного напряжения полупроводниковых диодов различного назначения (СВЧ-детекторы, параметрический усилитель, низкочастотный выпрямитель). Обнаружено, что диоды с частотой отсечки менее $100 \mathrm{MHz}$ проявляют детекторные свойства на $10 \mathrm{GHz}$.
\end{abstract}

Ключевые слова: полупроводниковый диод, детектирование, частота отсечки, СВЧ-колебания.

DOI: 10.21883/PJTF.2021.01.50449.18460

Механизм детектирования (выпрямления) низкочастотных (примерно до 10-100 MHz) колебаний полупроводниковыми диодами хорошо изучен $[1,2]$ и состоит в модуляции сопротивления области пространственного заряда (ОПЗ) при инжекции и вытягивании носителей заряда внешним электрическим полем. Однако при дальнейшем увеличении частоты поля эти процессы во многих типах полупроводниковых диодов не успевают установиться, и их детекторные (выпрямительные) свойства резко ухудшаются: наступает частотная отсечка.

Обычно для того, чтобы высота потенциального барьера в ОПЗ заметно изменилась для движения носителей, амплитуда приложенного напряжения должна быть сравнима с шириной запрещенной зоны полупроводника, что для кремниевых диодов соответствует амплитуде сигнала $V_{0} \approx 0.1 \mathrm{~V}$ и более. Поэтому большинство детекторных и смесительных диодов СВЧ работает при небольшом прямом смещении, за исключением низкобарьерных диодов Шоттки [3]. Характерно, что близость прямой вольт-амперной характеристики диодов с барьером Шоттки к теоретической при комнатной температуре не является достаточным критерием совершенства диода, а значит, и эффективной работы на СВЧ [4].

Отметим также, что в некоторых СВЧ-детекторных диодах (например, диод Д605) выпрямленное напряжение оказывается в 4-6 раз больше, чем $V_{0}$ падающей волны [5].

Оценка показывает, что в типичном кремниевом СВЧ-диоде (ширина ОПЗ $w \approx 1 \mu \mathrm{m}$, амплитуда сигнала $V_{0} \approx 1 \mathrm{mV}, \quad$ подвижность дырок в кремнии $\left.\mu_{p} \approx 500 \mathrm{~cm}^{2} /(\mathrm{V} \cdot \mathrm{s})\right)$ частота отсечки $f_{c}=\mu_{p} V_{0} / 2 w^{2} \approx 25 \mathrm{MHz}$. Следовательно, такие диоды независимо от площади перехода должны перестать детектировать на частотах выше $100 \mathrm{MHz}$. Однако на практике диоды с аналогичными параметрами работают в диапазоне СВЧ в качестве детекторов, смесителей и параметрических усилителей [2,6-8].

Интересные особенности детектирования (смена знака детектированного напряжения при росте $V_{0}$, влияние ориентации плоскости поляризации относительно плоскости диода) наблюдались в диодах металл-изолятор-металл (МИМ) [9-11]. Однако нам неизвестны подобные исследования на диодах с $p-n$-переходом.

Поэтому представляет интерес исследование частотной зависимости детекторных свойств диодов в широком диапазоне частот от сотен $\mathrm{kHz}$ до десятков $\mathrm{GHz}$, чтобы выяснить, как сказывается на таких свойствах диода переход через область частотной отсечки.

Для экспериментов были выбраны детекторные диоды, диоды для параметрического усиления СВЧ, а также выпрямительные (см. таблицу).

На частотах до $1 \mathrm{GHz}$ источником сигнала служил измеритель амплитудно-частотных характеристик X1-50 (коаксиальная линия), на частотах 9-10 GHz - амплитрон М-857 (волновод). Диод располагался в высокочастотной (СВЧ) линии так, чтобы электрическое поле СВЧ-волны было параллельно оси диода (т.е. перпендикулярно плоскости $p-n$-перехода или плоскости полупроводника, которой касается металлическая игла). Осциллограммы тока через диоды снимались на осциллографе C1-70 со стробоскопическим блоком 1 У71 (Я40-1700, полоса пропускания $3.5 \mathrm{GHz}$ ) и блоком развертки 1Р71 (Я40-2700).

Исследования показали, что в диодах ГА402 режим холостого хода нарушается при сопротивлении нагрузки $R_{L}<10^{6} \Omega$. Поэтому для измерения детектированного напряжения использовался вольтметр-электрометр ВК2-16 при входном сопротивлении $R_{\text {in }} \approx 100 \mathrm{M} \Omega$.

Экспериментальная частотная зависимость детектированного напряжения холостого хода $V_{o c}(f)$ диода 
Типы, технология, предельная частота и назначение исследованных диодов

\begin{tabular}{c|c|c|c}
\hline Тип & Технология и & $f_{c}, \mathrm{~Hz}$ & Назначение \\
диода (материал) & контакт & $10^{12}$ & Параметрический усилитель \\
\hline ГА402 $(\mathrm{Ge})$ & Диффузионный $p-n-$ & $10^{12}$ & Видеодетектор \\
ДК-В4(Si) & переход & $10^{12}$ & $\gg$ \\
ДК-В8 $(\mathrm{Si})$ & Точечный контакт & $10^{10}$ & $\gg$ \\
Д604 $(\mathrm{Si})$ & $\gg$ & $10^{10}$ & В \\
Д602(Ge) & $\gg$ & $3 \cdot 10^{9}$ & Выпрямитель
\end{tabular}

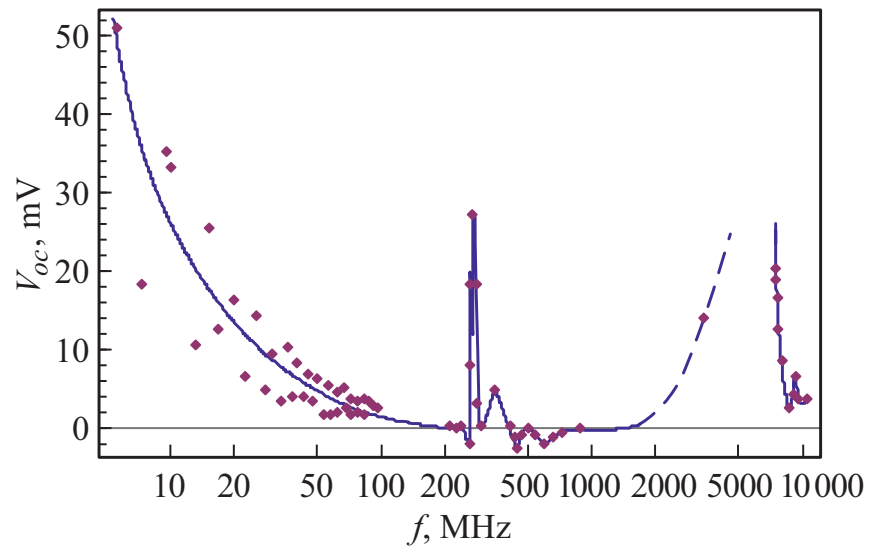

Рис. 1. Частотная зависимость выпрямленного напряжения холостого хода $V_{o c}$ диода ГА $402 Б$ при $P=1 \mathrm{~mW}$ и $T=300 \mathrm{~K}$. Точки - экспериментальные результаты, кривая - аппроксимация.

ГА402Б при постоянной мощности $P=1 \mathrm{~mW}$ генератора показана на рис. 1.

В диапазоне частот от 1 до $8.7 \mathrm{GHz}$ (кроме частоты $3 \mathrm{GHz}$, штриховой участок) измерения не проводились из-за отсутствия соответствующего генератора. На частотах $0.5-100 \mathrm{MHz}$ напряжение холостого хода $V_{o c}(f)$ уменьшается по мере повышения частоты как $f^{-1}$ согласно описанному выше и исчезает при $f>200 \mathrm{MHz}$. Однако около $300 \mathrm{MHz}$ в узком интервале частот возникает детектированное напряжение, причем оно несколько раз меняет знак с ростом частоты и при $f \geqslant 800 \mathrm{MHz}$ снова исчезает. На частотах более $8.7 \mathrm{GHz}$ наблюдается немонотонно уменышающееся детектированное напряжение $V_{\text {oc }}(f)$.

При этом с уменьшением подводимой мощности $V_{o c}(f)$ становится положительным на всех частотах. Такое поведение $V_{o c}$ примечательно тем, что изменение знака $V_{o c}$ происходит при $P<1 \mathrm{~mW}$, в то время как в 3-сантиметровом диапазоне для этого требуется мощность более $100 \mathrm{~mW}$. Физическая природа этих особенностей пока не установлена, но предполагается, что они связаны с неоднородностью плазмы полупроводниковых структур.

Величина детектированного напряжения $V_{o c}$ на частотах около $300 \mathrm{MHz}$ и $9 \mathrm{GHz}$ сравнима с таковой
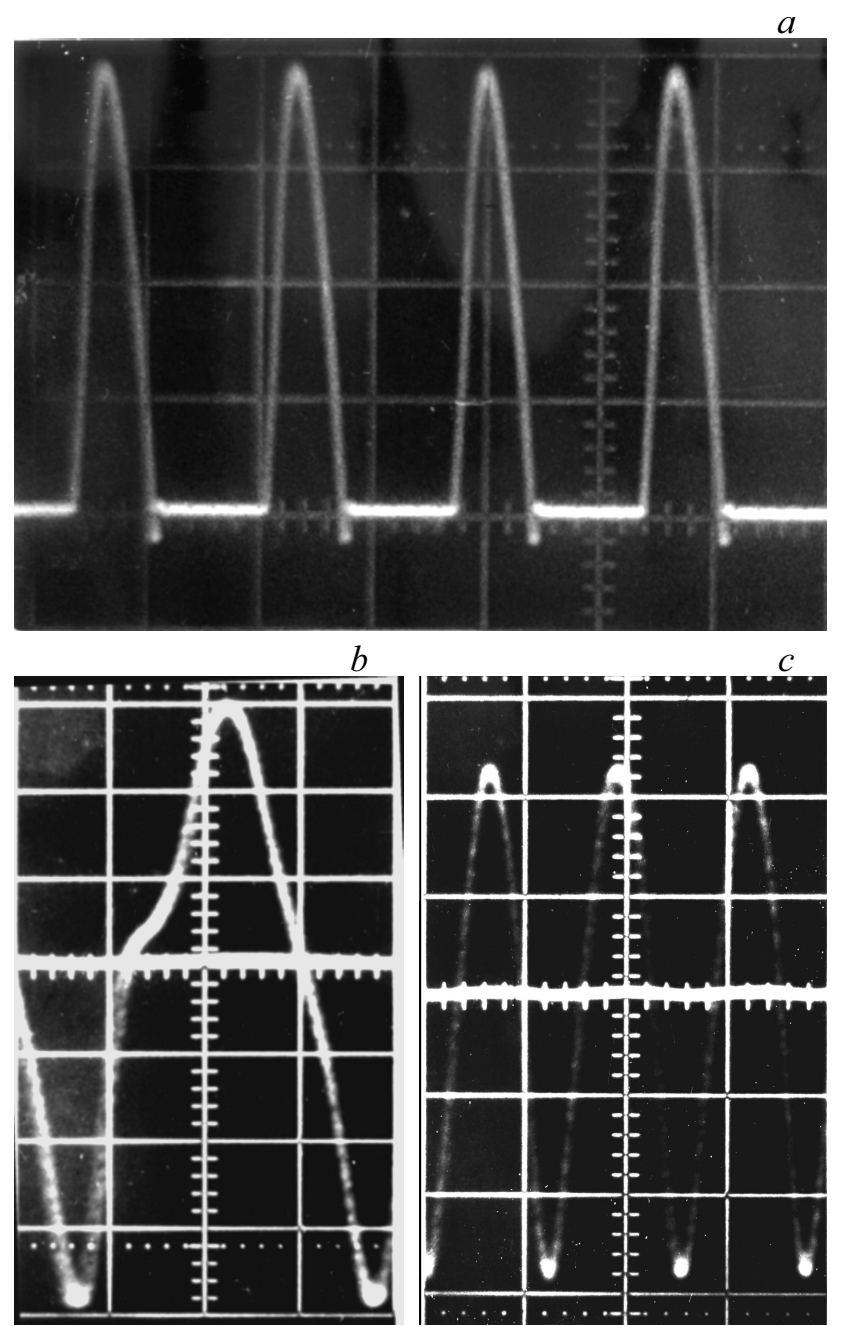

Рис. 2. Осциллограммы высокочастотного тока через диод ГА $402 Б$ на частоте $0.3(a), 300(b)$ и $900 \mathrm{MHz}(c)$. Цена деления по горизонтали: $2 \mu \mathrm{s} / \operatorname{div}(a), 1 \mathrm{~ns} / \operatorname{div}(b, c)$. Цена деления по вертикали: $0.65 \mathrm{~mA} / \mathrm{div}$. 


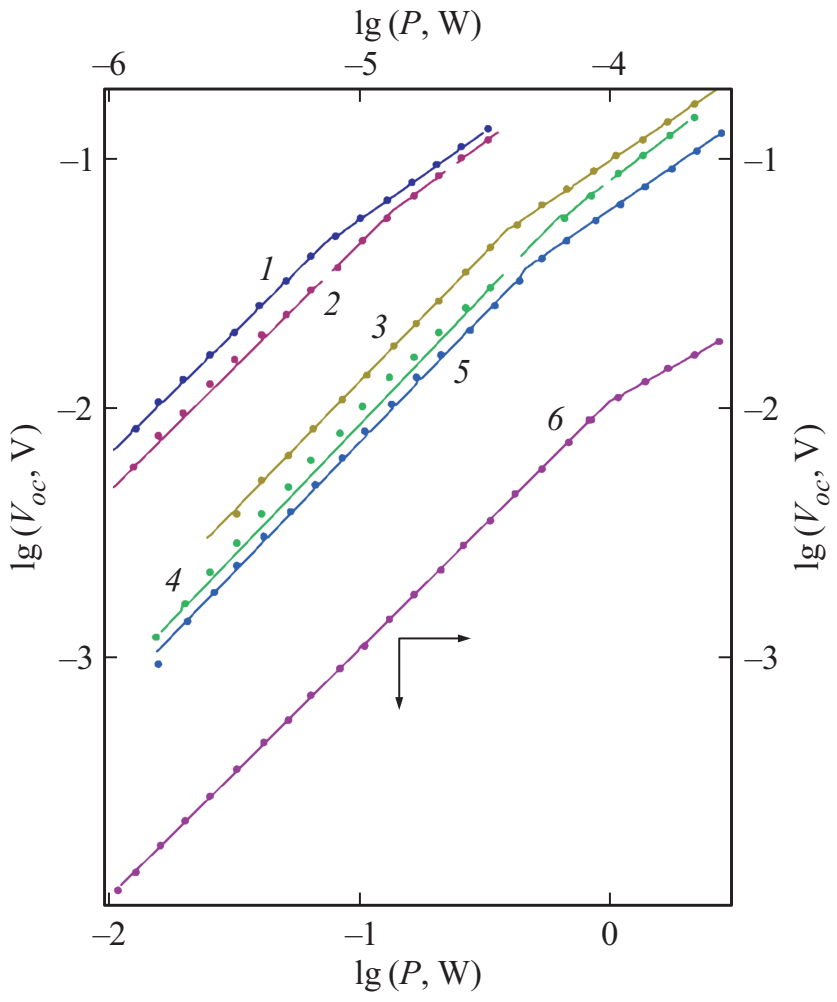

Рис. 3. Зависимость от мощности $P$ детектированного напряжения холостого хода $V_{o c}$ диодов Д604 (1), ГА402Б (2), Д602А (3), ДКИ-1М (4), ДК-В4 (5) и 2Ц106 (6). $\omega=6 \cdot 10^{10} \mathrm{~s}^{-1}, T=300 \mathrm{~K}$. Параметры диодов приведены в таблице.

на частотах ниже $1 \mathrm{MHz}$ при одинаковой мощности сигнала.

Исчезновение детекторных (выпрямляющих) свойств диода ГА 4025 на частотах более $200 \mathrm{MHz}$ подтверждается и осциллограммами тока через диод в том же диапазоне частот (рис. 2).

Как видно из этих осциллограмм, в диоде ГА402Б на частотах порядка $1 \mathrm{MHz}$ действительно имеет место выпрямление (рис. 2, a), но по мере повышения частоты обратный ток через диод возрастает (рис. $2, b$ ) и на частотах около $1 \mathrm{GHz}$ (в $10^{3}$ раз ниже предельной частоты, рис. $2, c)$ становится практически синусоидальным, диод уже не проявляет выпрямительных свойств (асимметрии высокочастотного тока).

Аналогично меняется на тех же частотах высокочастотный ток через СВЧ-видеодетектор ДК-В8 с тем отличием, что обратный ток имеет форму полусинусоиды, амплитуда которой на частоте $0.15 \mathrm{MHz}$ в 5 раз меньше, чем для положительной полуволны, но с ростом частоты это отношение уменьшается до 1 .

Тем не менее эти диоды, а также диоды, предназначенные для выпрямления на частотах порядка десятков $\mathrm{kHz}$, проявляют детекторные свойства на частоте $\omega=6 \cdot 10^{10} \mathrm{~s}^{-1}$ (рис. 3). Здесь примечательно, что у всех диодов, включая даже выпрямительный диод $2 Ц 106$, начальный участок зависимости $V_{o c}(P)$ линейный, т.е. детектирование квадратичное, и при достижении некоторой величины $P$ наблюдается излом $V_{o c}(P)$, после чего наклон уменьшается.

Эти результаты показывают следующее.

1. Возникновение участков детектирования высокочастотного сигнала $V_{o c}(f)$ выше частоты отсечки (ГА402Б) и выше предельной рабочей частоты (2Ц106) не согласуется с общепринятой теорией выпрямления и связанной с ней частотной отсечкой, а физический механизм такого поведения остается неясным.

2. Влияние ориентации плоскости поляризации падающего излучения относительно плоскости МИМ-диода указывает на то, что в детектировании оптического и теплового излучения важна не только энергия фотона, но и его волновые свойства.

\section{Конфликт интересов}

Авторы заявляют, что у них нет конфликта интересов.

\section{Список литературы}

[1] S.M. Sze, Modern semiconductor device physics (Wiley, N.Y., 1998). [С. Зи, Физика полупроводниковых приборов (Мир, М., 1984), кн. 2.].

[2] Microwave semiconductor devices and their circuit applications, ed. by H.A. Watson (McGRAW-Hill Book Company, N.Y., 1969). [СВЧ-полупроводниковые приборы и их применение, под ред. Г. Уотсона (Мир, М., 1972)].

[3] $R F$ and microwave power detection with Schottky diodes. Application Notes. (Infineon, 2018).

[4] В.Г. Божков, В.С. Лукаш, Вестн. Томск. гос. ун-та, №285, 129 (2005)

http://sun.tsu.ru/mminfo/000063105/285/image/285-129.pdf

[5] Сверхвысокочастотные детекторные диоды для детектирования сигналов СВЧ-диапазона, технические характеристики, параметры.

https://eandc.ru/news/detail.php?ID $=18813$

[6] https://www.infineon.com/dgdl/Infineon-AN_1807_PL32_ 1808_132434_RF and microwave power detection-ANv01_00-EN.pdf

[7] S.K. Roy, M. Mitra, Microwave semiconductor devices (Prentice-Hall of India, New Delhi, 2006).

[8] J.A. Hagerty, Nonlinear circuits and antennas for microwave energy conversion, PhD Thesis (University of Colorado, 2003).

[9] S.P. Kwok, G.I. Haddad, G. Lobov, J. Appl. Phys., 42 (2), 554 (1971). https://doi.org/10.1063/1.1660062

[10] M. Pyee, J. Uebersfeld, J. Auvray, C. Gastaud, Proc. IEEE, 62 (4), 526 (1974). DOI: 10.1109/PROC.1974.9462

[11] T.K. Gustafson, R.V. Schmidt, J.R. Perucca, Appl. Phys. Lett., 24 (12), 620 (1974). https://doi.org/10.1063/1.1655078 